\title{
Ask not what your Fontan can do for you, ask what you can do for your Fontan!
}

\author{
Yves d'Udekem, MD, PhD, FRACS, ${ }^{\mathrm{a}, \mathrm{b}, \mathrm{c}}$ Nimani Fernando, MSc, ${ }^{\mathrm{c}}$ and Karin du Plessis, $\mathrm{PhD}^{\mathrm{b}, \mathrm{c}}$
}

\footnotetext{
From the ${ }^{a}$ Cardiac Surgery Department, Royal Children's Hospital, Melbourne, Victoria, Australia; ${ }^{\mathrm{b}}$ Department of Pediatrics, Faculty of Medicine, The University of Melbourne, Melbourne, Victoria, Australia; and ${ }^{\mathrm{c}}$ Murdoch Children's Research Institute, Melbourne, Victoria, Australia.

This work was supported by a National Health and Medical Research Council Partnership Grant (1076849) Y.d'U. is a Clinician Practitioner Fellow of the National Health and Medical Research Council (1082186).

Received for publication Sept 13, 2017; revisions received Oct 26, 2017; accepted for publication Nov 9, 2017; available ahead of print April 13, 2018.

Address for reprints: Yves d'Udekem, MD, PhD, FRACS, The Royal Children's Hospital Melbourne, 3 West Clinical Offices, 50 Flemington Rd, Parkville, Victoria, 3052, Australia (E-mail: yves.dudekem@rch.org.au). J Thorac Cardiovasc Surg 2018; 156:249-51

$0022-5223 / \$ 36.00$

Copyright (C) 2018 by The American Association for Thoracic Surgery

https://doi.org/10.1016/j.jtcvs.2017.11.122
}

There are several reasons why patients born with a single ventricle are so important for cardiac surgeons. Their survival represents the highest achievement of our community, their long-term outcomes are our current biggest challenge, and, importantly, we are emotionally bound to this population. They all required several procedures, and we watched them grow and know them so well that usually we call their parents by their first name.

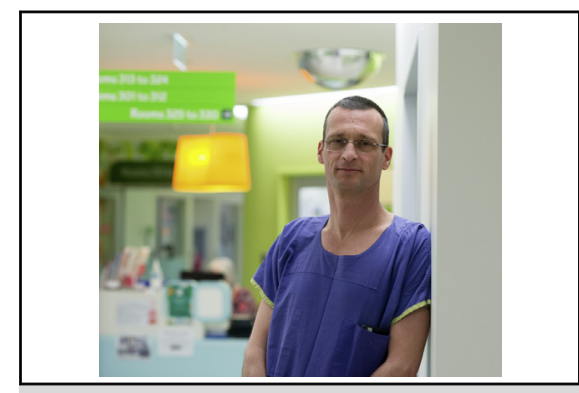

Yves d'Udekem, MD, PhD, FRACS, Chair of the Australian and New Zealand Fontan Registry.

\section{Central Message}

We should continue to provide surgical interventions that optimize the Fontan circulation for the best long-term outcomes. Patients also should maintain high levels of exercise activity for their Fontan.

See Editorial Commentary page 252

\section{NEW DATA ON FONTAN OUTCOMES}

There have been several recent research developments that are worth highlighting to clinicians concerned with the fate of patients with a single ventricle. Atz and colleagues $^{1}$ reported the analysis of the third crosssectional assessment of the Pediatric Heart Network study. This is the most carefully studied and largest longitudinal cohort of patients who have undergone the Fontan. An extensive functional study was performed in 343 of the 546 patients enrolled in the original cohort, 9 years after their initial assessment. Transplant-free survival of this selected cohort was $90 \%$, a number that was expected considering a likely selection of sicker patients. The most concerning findings were, that over time, the ejection fraction and exercise capacity of these patients were declining, even in the youngest fraction of this cohort.

In recent years, the Australian and New Zealand Fontan Registry has provided population-based data extending to 35 years, demonstrating better survival after the Fontan than expected and the unstoppable growth of this population. $^{2-4}$ Two thirds of those operated with the classic atriopulmonary Fontan were still alive 30 years after Fontan completion, and two thirds of these survivors were employed at last follow-up. ${ }^{2}$

There are also some individual center experiences that are worth following closely. The team from Osaka is overseeing the care of a population of 400 patients with the most complete imaginable set of investigations. ${ }^{5,6}$ They, like others, had also previously highlighted the steady decline in exercise capacity of the Fontan population, even from a young age. ${ }^{7-9}$ They have now demonstrated that impairment of renal function noted in some of the patients may affect their longevity, highlighting for the first time the relationship between survival and end-organ damage inflicted by the Fontan circulation. ${ }^{5}$

\section{SO, WHERE DO WE STAND?}

There may be up to 70,000 patients with a Fontan circulation in the world. These are extrapolated estimates arising from the population-based data of the Australian and New Zealand Registry, and the number of procedures performed in North America. ${ }^{3,10}$ There is no doubt that this population is steadily growing. Today, $40 \%$ of this population is composed of adults. ${ }^{3}$ Those with a Fontan circulation have a heavy burden of disease, with at least half of them affected by a serious complication before they reach adulthood. ${ }^{11}$ These complications range from strokes and arrhythmias to thromboembolic events and reoperations. We are just unveiling the impact of the elevated central venous pressures on the liver and kidneys. ${ }^{12}$ Although this picture may seem concerning, anybody who is in contact with a large number of these patients would know that the majority of them are not crippled or debilitated. They are active members of our society, engaged in the full spectrum of employment. Before our vision of this population is 
tainted by too much pessimism, we should make sure that we have made every effort possible to improve their fate. Fortysix years after its original description, we still do not fully understand the physiologic mechanisms of this circulation. We have not yet established to what extent end-organ damage may affect the outcomes of those with a Fontan circulation. We also do not have many ideas on the best way to follow them and have not determined yet which treatment will best preserve their life.

\section{THE REAL QUESTION}

The most crucial and still unresolved question is whether the Fontan circulation is intrinsically incompatible with a long near-normal life. The overall Fontan population has been deteriorating in time since a very early age, but is this the case for every one of them, and does this occur since the onset of the Fontan circulation? All the studies have been performed in patient groups including those with the worst outcomes; the Pediatric Heart Network study at initiation of the cohort included adult patients with an atriopulmonary Fontan, a significant proportion of patients with hypoplastic left heart syndrome, and a large number of patients with atrioventricular valve regurgitation. We expect that most of them would deteriorate over the 9 years of the current follow-up, but what about the others? We still do not know whether children with no single risk factor of adverse outcomes will also see a deterioration of their ventricular function and exercise capacity as they reach adolescence and early adulthood. There are some indications that patients with the best hemodynamic characteristics do not see this decline in their exercise capacity. ${ }^{9}$ Answering this question is crucial for our surgical community, because it may push us to address the modifiable factors in those who have already undergone operation. If some patients can live seemingly unaffected with a Fontan circulation for several decades, then we should try to improve the factors that may adversely affect their outcomes, such as mild distortion of their Fontan circuitry, hypoplastic pulmonary arteries, suboptimal arch anatomy, and atrioventricular and semi-lunar valve regurgitation. The incidence of these issues seems far more important than the number of reinterventions performed in these patients. We can also investigate strategies that will better preserve their ventricular function before they reach the Fontan. ${ }^{13}$ This is the work that we surgeons can provide. Until we have created a population with a perfect Fontan circuitry, large pulmonary arteries, no valvular regurgitation, no arch obstruction, and a preserved ventricular function, there will be work left for us to improve the Fontan population.

\section{WHAT CAN WE DO?}

Despite the numerous challenges facing the Fontan population and the uncertainty about the best medical treatment that would prevent their demise, there has been to date only a handful of trials that have had more than 20 patients with a Fontan circulation. $^{14-18}$ We now understand that individual research projects performed in isolated centers are unlikely to provide answers in the timeframe that would improve the outcomes of our existing population. We need to build large international collaborations with researchers from diverse horizons. We need to gather in this effort specialties as varied but not limited to neurology, psychology, gastroenterology, hematology, and endocrinology. One emerging initiative is the recently created International Fontan Interest Group, which aims to better understand the Fontan circulation and develop the research platform necessary to improve the late outcomes of this population. ${ }^{19}$

It is becoming increasingly clear that a large portion of those with a failing Fontan circulation will require mechanical support, either because they will not be good candidates for heart transplantation or because of the scarcity of organ donors. We are only at the beginning of our experience with mechanical support of the Fontan circulation, and we still have to determine the best way to use current devices and indications of support, and ideally, we should try to develop devices specifically designed for the Fontan circulation. ${ }^{20-23}$

The patients themselves and their families today also have a large responsibility to improve their own outcomes. There is increasing evidence that exercise training, even when performed for a limited number of weeks, increases cardiac output at maximum exercise, an effect that is linked to the building of muscle mass in the lower limbs. ${ }^{24-26}$ Also, a training regimen of inspiratory respiratory muscles results in an increase of baseline resting cardiac output. ${ }^{27}$ One of the fascinating findings of the recent Pediatric Heart Network study was that increased physical activity levels at the initiation of the cohort was predicting higher chances of transplant-free survival. ${ }^{1}$ Today, the most effective way to have the best possible late outcomes after the Fontan seems to be the adoption of a healthy lifestyle, including a high level of physical activity and exercise training. A healthy lifestyle regimen seems by far more important in patients with a single ventricle than in those with 2 ventricles.

The recent data on Fontan outcomes seem to indicate that the Fontan circulation may be subjected to a progressive degradation. Before we despair about the future of this expanding population, we as health practitioners should complete the necessary work to provide them with the best possible outcomes. Through surgery or interventional catheterization, we should optimize their circulation and complete the research necessary to identify the best medical therapy to prevent their complications. Patients, on the other hand, should adhere to a regular and strict discipline of sustained exercise activity. 
Ask not what your Fontan can do for you, ask what you can do for your Fontan!

\section{Conflict of Interest Statement}

Y.d'U. is a consultant for the companies MSD and Actelion. The authors take responsibility for all aspects of the reliability and freedom from bias of the data presented and their discussed interpretation. All other authors have nothing to disclose with regard to commercial support.

\section{References}

1. Atz AM, Zak V, Mahony L, Uzark K, Dágincourt N, Goldberg DJ, et al. Longitudinal outcomes of patients with single ventricle after the Fontan procedure. $J$ Am Coll Cardiol. 2017;69:2735-44.

2. Poh CL, Zannino D, Weintraub RG, Winlaw DS, Grigg LE, Cordina R, et al. Three decades later: the fate of the population of patients who underwent the atriopulmonary Fontan procedure. Int J Cardiol. 2017;231:99-104.

3. Schilling C, Dalziel K, Nunn R, Du Plesssis K, Shi WY, Celermajer D, et al. The Fontan epidemic: population projections from the Australia and New Zealand Fontan Registry. Int J Cardiol. 2016;219:14-9.

4. d'Udekem Y, Iyengar AJ, Galati JC, Forsdick V, Weintraub RG, Wheaton GR, et al. Redefining expectations of long-term survival after the Fontan procedure: twenty-five years of follow-up from the entire population of Australia and New Zealand. Circulation. 2014;130(11_suppl_1):S32-8.

5. Ohuchi H, Negishi J, Hayama Y, Miyazaki A, Shiraishi I, Ichikawa H. Renal resistive index reflects Fontan pathophysiology and predicts mortality. Heart. 2017; 103:1631-7.

6. Ohuchi H, Miyazaki A, Negishi J, Hayama Y, Nakai M, Nishimura K, et al. Hemodynamic determinants of mortality after Fontan operation. Am Heart J. 2017; 189:9-18.

7. Fernandes SM, McElhinney DB, Khairy P, Graham DA, Landzberg MJ, Rhodes J. Serial cardiopulmonary exercise testing in patients with previous Fontan surgery. Pediatr Cardiol. 2010;31:175-80.

8. Ovroutski S, Ewert P, Miera O, Alexi-Meskishville V, Peters B, Hetzer R, et al. Long-term cardiopulmonary exercise capacity after modified Fontan operation. Eur J Cardiothorac Surg. 2010;37:204-9.

9. Ohuchi H, Ono S, Tanabe Y, Fujimoto K, Yagi H, Sakaguchi H, et al. Long-term serial aerobic exercise capacity and hemodynamic properties in clinically and hemodynamically good, “excellent,” Fontan survivors. Circ J. 2012;76:195-203.

10. Jacobs JP, Mayer JE, Mavroudis C, O’Brien SM, Austin EH III, Pasquali SK, et al. The Society of Thoracic Surgeons congenital heart surgery database: 2017 update on outcomes and quality. Ann Thorac Surg. 2017;103:699-709.

11. Iyengar AJ, Winlaw DS, Galati JC, Wheaton GR, Gentles TL, Grigg LE, et al. The extracardiac conduit Fontan procedure in Australia and New Zealand: hypoplastic left heart syndrome predicts worse early and late outcomes. Eur J Cardiothorac Surg. 2014;46:465-73.

12. Rychik J. The relentless effects of the Fontan paradox. Semin Thorac Cardiovasc Surg Pediatr Card Surg Annu. 2016;19:37-43.
13. Asakai H, Galati JC, Weskamp S, Jones B, Millar J, Konstantinov IE, et al Impact of Blalock-Taussig shunt size on tricuspid regurgitation in hypoplastic left heart syndrome. Ann Thorac Surg. 2014;97:2123-8.

14. Kouatli AA, Garcia JA, Zellers TM, Weinstein EM, Mahony L. Enalapril does not enhance exercise capacity in patients after Fontan procedure. Circulation. 1997;96:1507-12.

15. Giardini A, Balducci A, Specchia S, Gargiulo G, Bonvicini M, Picchio FM Effect of sildenafil on haemodynamic response to exercise and exercise capacity in Fontan patients. Eur Heart J. 2008;29:1681-7.

16. Schuuring MJ, Vis JC, van Dijk APJ, Vilegen HW, Pieper PG, Sieswerda GT, et al. Impact of bosentan on exercise capacity in adults after the Fontan procedure: a randomized controlled trial. Eur J Heart Fail. 2014;15:690-8.

17. Goldberg DJ, French B, McBride MG, Marino BS, Mirarchi N, Hanna BD, et al Impact of oral sildenafil on exercise performance in children and young adults after the Fontan operation: a randomized, double-blind, placebo-controlled, crossover trial. Circulation. 2011;123:1185-93.

18. Hebert A, Mikkelsen UR, Thilen U, Idorn L, Jensen AS, Nagy E, et al. Bosentan improves exercise capacity in adolescents and adults after Fontan Operation: the TEMPO (treatment with endothelin receptor antagonist in Fontan patients, a randomized, placebo-controlled, double-blind study measuring peak oxygen consumption) study. Circulation. 2014;130:2021-30.

19. d'Udekem Y, Rychik J. Towards the goal of achieving a normal duration and quality of life after Fontan operation: creation of the international Fontan interest group (I-FIG), an international collaborative initiative dedicated to improving outcomes. Int J Cardiol. 2017;245:131-4.

20. Rodefeld MD, Frankel SH, Giridharan GA. Cavopulmonary assist: (Em)powering the univentricular Fontan circulation. Semin Thorac Cardiovasc Surg Pediat Card Surg Annu. 2011;14:45-54.

21. Nandi D, Miller KD, Bober CM, Rosenthal TM, Montenegro LM, Rossano JW et al. Systemic atrioventricular valve excision and ventricular assist devices in pediatric patients. Ann Thorac Surg. 2018;105:170-4.

22. Poh CL, Chiletti R, Zannino D, Brizard C, Konstantinov IE, Horton S, et al. Ventricular assist device support in patients with single ventricles: the Melbourne experience. Interact Cardiovasc Thorac Surg. 2017;25:310-6.

23. Prêtre R, Häussler A, Bettex D, Genoni M. Right-sided univentricular cardiac assistance in a failing Fontan circulation. Ann Thorac Surg. 2008;86: 1018-20.

24. Sutherland N, Jones B, d'Udekem Y. Should we recommend exercise after the Fontan procedure? Heart Lung Circ. 2015;24:753-68.

25. Cordina RL, O'Meagher S, Karmali A, Rae CL, Liess C, Kemp GJ, et al Resistance training improves cardiac output, exercise capacity and tolerance to positive airway pressure in Fontan physiology. Int J Cardiol. 2013;168 780-8.

26. Cordina R, O'Meagher S, Gould H, Rae C, Kemp G, Pasco JA, et al. Skeletal muscle abnormalities and exercise capacity in adults with a Fontan circulation. Heart. 2013;99:1530-4.

27. Laohachai K, Winlaw D, Selvadurai H, Gnanappa GK, d'Udekem Y, Celermajer D, et al. Inspiratory muscle training is associated with improved inspiratory muscle strength, resting cardiac output, and the ventilatory efficiency of exercise in patients with a Fontan circulation. J Am Heart Assoc. 2017;6: $\mathrm{e} 005750$. 